\title{
Fatores que influenciam na adesão vacinal de mães usuárias da Atenção Primária à
}

\section{Saúde}

\author{
Factors influencing vaccine access by mother's users of the Primary Healt Care \\ Factores que influyen em el acceso a las vacunas por parte de las madres usuarias de la Atención \\ Primaria de Salud
}

Recebido: 22/03/2021 | Revisado: 28/03/2021 | Aceito: 30/03/2021 | Publicado: 10/04/2021

\author{
Daltro Moreira Iori \\ ORCID: https://orcid.org/0000-0001-7154-4345 \\ Centro Universitário de Maringá, Brasil \\ E-mail: daltro.iori@gmail.com \\ Valéria Maria Carvalho Siqueira \\ ORCID: https://orcid.org/0000-0001-9860-5275 \\ Centro Universitário de Maringá, Brasil \\ E-mail: valeria_mcs2@gmail.com \\ Caroline Rodrigues de Almeida \\ ORCID: https://orcid.org/0000-0001-9740-4623 \\ Centro Universitário de Maringá, Brasil \\ E-mail: caroline.almeida@unicesumar.edu.br \\ Célia Maria Gomes Labegalini \\ ORCID: https://orcid.org/0000-0001-9469-4872 \\ Universidade Estadual do Paraná, Brasil \\ E-mail: celia.labegalini@gmail.com
}

\begin{abstract}
Resumo
Objetivo: Analisar os fatores que influenciam as mães na adesão vacinal. Metodologia: Pesquisa qualitativa, exploratória e descritiva, realizada com 18 mães que utilizam uma Unidade Básica de Saúde. Os dados foram coletados por meio de entrevista apoiada por um roteiro, estes foram transcritos e submetidos a análise temática. Seguiram-se todos os preceitos éticos vigentes. Resultados: Participaram do estudo 18 mulheres, com idades entre 20 e 39 anos, as mães ressaltam que o principal benefício da vacinação é a prevenção e proteção para algumas doenças transmissíveis, em relação aos possíveis malefícios as mesmas destacam que os benefícios os superam. A respeito dos impactos da diminuição da cobertura vacinal, as mães deste estudo ressaltam que pode haver a eminência de seus filhos contraírem doenças infecto contagiosas devido a lacuna imunológica que seria suprida pela vacina. Conclusão: O estudo identificou que as mães são as principais responsáveis pela vacinação das crianças, e o principal fator para a adesão vacinal é a prevenção e proteção para algumas doenças transmissíveis. As participantes relatam que os benefícios da imunização superam os malefícios, e estes se relacionam a possiblidade de efeitos adversos, e a dor durante o procedimento invasivo.

Palavras-chave: Cobertura Vacinal; Imunização; Programas de imunização; Unidade básica de saúde; Atenção primária à saúde.

Abstract

Objective: To analyze the factors that influence mothers in vaccination adherence. Methodology: Qualitative, exploratory and descriptive research, carried out with 18 mothers who use a Basic Health Unit. Data were collected through interviews supported by a script, these were transcribed and submitted to thematic analysis. All current ethical precepts were followed. Results: 18 women, aged between 20 and 39 years, participated in the study. The mothers emphasize that the main benefit of vaccination is the prevention and protection for some communicable diseases, in relation to possible harm they emphasize that the benefits outweigh them. Regarding the impacts of reduced vaccination coverage, the mothers in this study point out that there may be an eminence of their children to contract contagious infectious diseases due to the immunological gap that would be supplied by the vaccine. Conclusion: The study identified that mothers are the main responsible for the vaccination of children, and the main factor for vaccine adherence is the prevention and protection for some communicable diseases. Participants report that the benefits of immunization outweigh the harm, and these are related to the possibility of adverse effects, and pain during the invasive procedure.
\end{abstract}

Keywords: Vaccination coverage; Immunization; Immunization programs; Basic health unit; Primary health care. 


\section{Resumen}

Objetivo: Analizar los factores que influyen en las madres en la adherencia a la vacunación. Metodología: Investigación cualitativa, exploratoria y descriptiva, realizada con 18 madres que utilizan una Unidad Básica de Salud. Los datos fueron recolectados a través de entrevistas sustentadas en un guión, estas fueron transcritas y sometidas a análisis temático. Se siguieron todos los preceptos éticos vigentes. Resultados: Participaron del estudio 18 mujeres entre 20 y 39 años, las madres enfatizan que el principal beneficio de la vacunación es la prevención y protección de algunas enfermedades transmisibles, en relación a los posibles daños enfatizan que los beneficios los superan. En cuanto a los impactos de la reducción de las coberturas de vacunación, las madres de este estudio señalan que puede existir una eminencia de sus hijos para contraer enfermedades infecciosas contagiosas debido al vacío inmunológico que sería suplido por la vacuna. Conclusión: El estudio identificó que las madres son las principales responsables de la vacunación de los niños y el principal factor de adherencia a la vacuna es la prevención y protección de algunas enfermedades transmisibles. Los participantes informan que los beneficios de la inmunización superan a los daños y estos están relacionados con la posibilidad de efectos adversos y dolor durante el procedimiento invasivo.
\end{abstract}

Palabras clave: Cobertura de vacunación; Inmunización; Programas de inmunización; Atención primaria de salud.

\title{
1. Introdução
}

O Programa Nacional de Imunizações (PNI), criado em 1973, organiza e implementa o calendário vacinal no Brasil, assim, garante ações de prevenção à saúde previstas na legislação do Sistema Único de Saúde. Este contribuiu para o controle e erradicação de doenças infecto contagiosas, por meio imunização sistemática da população brasileira, reduzindo as taxas de morbidade e mortalidade por doenças previsíveis, inclusive erradicando algumas doenças no país (Yuzawa, Ferreira \& Oliveira, 2019; Nascimento, Cavalcanti \& Silva, 2020).

A efetividade do programa, bem como o número de imunobiológicos ofertados de forma gratuita em todo território nacional, faz com que o PNI seja uma referência mundial, reconhecido pela Organização Pan Americana da Saúde (OPAS) (Nascimento, Cavalcanti, Silva, 2020; Domingues, et al. 2020).

Entretanto as taxas de vacinação nacionais estão em declínio desde 2016, tal fato pode ser relacionado a preocupação com eventos adversos, a crença de que não é essencial vacinar as crianças pelo fato de certas doenças terem recebido o certificado de erradicação e alguns movimentos sociais anti-vacinação. A diminuição da cobertura vacinal já levou a epidemias de sarampo em 2017, em Roraima e no Amazonas (Sato, 2018; Passos \& Moares Filho, 2020), e fez o tema ser alvo de inquéritos do Ministério da Saúde, a fim de entender tal fenômeno e seus influentes.

O direito a imunização está previsto no Estatuto da Criança e do Adolescente (ECA), o qual deve ser garantido pelos pais e responsáveis. Entretanto a temática é complexa, envolve aspectos culturais, sociais e econômicos que variam ao longo do tempo e do tipo da vacina. Ainda, deve-se considerar as premissas de subjetividade e o cuidado parental, o qual ultrapassa a perspectiva da bioética e da Saúde Pública, tornando a temática campo fértil para a realização de pesquisas (Paes, 2018; Sato, 2018).

Considerando os benefícios individuais e sociais da adesão vacinal na saúde infantil, bem como as diferentes perspectivas de cuidado, os quais permeiam o momento histórico vigente, faz-se necessário compreender os fatores relacionados a adesão a vacina por mães usuárias do serviço público de saúde. O estudo foi delineado a partir da seguinte pergunta: Quais os influentes das mães na decisão de vacinar os filhos? Assim, objetivou- se analisar os fatores que influenciam as mães na adesão vacinal.

\section{Metodologia}

Pesquisa qualitativa, do tipo exploratória e descritiva. Realizada com 18 mães que utilizam uma Unidade Básica de Saúde (UBS) localizada em um Município do Norte do Estado do Paraná. Critérios de inclusão: realizar pré-natal e puericultura na UBS; ser mãe de criança menor de 5 anos. Critério de exclusão: ter menos de 18 anos. O local de pesquisa foi 
uma UBS localizada em Maringá-PR, a mesma possui organização semanal para consultas de pré-natal e puericultura, realizadas pelos profissionais enfermeiro e médico, a vacinação é realizada pelos técnicos de enfermagem todos os dias

Os dados foram coletados utilizando roteiro semiestruturado elaborado pelos pesquisadores, composto de questões referentes à caracterização e ao conhecimento sobre a imunização e a adesão à vacinação de seus filhos. As participantes foram abordadas de forma aleatória na UBS enquanto aguardavam atendimento. A entrevista foi gravada em áudio e realizada em sala reservada, com duração média de seis minutos. A coleta foi realizada entre os meses de Setembro e Novembro de 2019, em dias da semana e períodos distintos.

Os dados foram transcritos na íntegra, organizados e analisados por análise temática de conteúdo (Bardin, 2011), a o qual as organiza em três fases: 1) pré-análise, 2) exploração do material e 3) tratamento dos resultados, inferência e interpretação.

A pesquisa seguiu todas as premissas da Resolução no 466/2012, com parecer favorável do Comitê de Ética em Pesquisa do Centro Universitário de Maringá (UNICESUMAR), sob número 3.474.487/2019 (CAAE: 17151119.3.0000.5539). A fim de garantir o anonimato e o sigilo dos dados, os participantes foram identificados com a letra " $E$ " de entrevistado, seguido de números arábicos, seguindo a ordem de transcrição das entrevistas.

\section{Resultados e Discussão}

Participaram do estudo 18 mulheres, com idades entre 20 e 39 anos (idade média de 29,1). Em relação à escolaridade duas possuem ensino fundamental incompleto, uma possui ensino fundamental, oito ensino médio, uma refere possuir ensino superior incompleto, cinco superior completo e uma especialização. No que se refere a ocupação, oito possuem emprego formal, quatro atuam como autônomas, três empregas domésticas, duas como profissionais liberais e uma estudante.

A participantes do estudo são predominantemente ( $n=12)$ casadas ou vivem em união estável, ainda cinco são solteiras e uma divorciada. A mulheres relatam possuírem entre um e quatro filhos (média de 1,9 filhos).

Em relação a imunização, as mães ressaltam que o principal benefício da vacinação é a prevenção e proteção para algumas doenças transmissíveis, conforme exemplificado nas falas a seguir:

"Eu entendo a importância da vacinação, principalmente, pela saúde dos meus filhos, para que eles não possam vir a ter nenhuma doença equivalente aquele tipo de vacina ofertada [...].” E16

“Existem vários benéficos [na vacinação], o mais importante é proteger contra alguns tipos de doenças." E9

“Para proteger contra doenças, inclusive devido as vacinas algumas já foram até erradicadas[...]." E14

"As vacinas servem para prevenir doenças, acredito que seja mais ou menos isso, mas sei que é importante vacinar [...]."E17

A vacina se tornou, desde a década de 70, um dos meios mais eficazes e com melhor custo-benefício para a prevenção individual e coletiva de doenças infectocontagiosas. Esta estimula o sistema imunológico na produção de anticorpos específicos contra o agente infeccioso e seus produtos tóxicos, bem como ativa os linfócitos para a formação de células de memória, as quais armazenam informações para que o corpo possa ter uma resposta fisiológica mais rápida e eficiente em contatos futuros com o micro-organismo, formando a imunidade ativa (Martins, Santos \& Álvares, 2019; Nascimento, Cavalcanti \& Silva, 2020).

O processo de vacinação coletiva leva a diminuição da circulação do micro-organismo, controlando e erradicando diversas doenças, por isso trata-se de uma das principais e mais eficazes estratégias de prevenção a saúde, especialmente na 
primeira infância. A adesão vacinal é importante para a prevenção coletiva, e depende principalmente dos pais. Por isso, esses precisam ter clareza quando a função, riscos e benefícios dos imunobiológicos, assim profissionais de saúde devem educar a população sobre essas temáticas, destacando o papel dos pais na proteção e cuidado com o filho (Santos, et al. 2011; Aps, et al. 2018; Mendes et al. 2020).

Dessa forma, a prevenção de doenças infectocontagiosas torna-se a principal motivação para a vacinação, segundo as participantes a possibilidade de manter os filhos saudáveis é uma das formas de cuidado e proteção parental para com prole. Conforme falas a seguir:

"Eu vacino meu filho por proteção. Eu tinha um pouco de desconhecimento sobre a vacina da gripe, mas hoje eu já mudei meu pensamento. Devido a onda de contaminação por sarampo eu vi que o que está acontecendo hoje [aumento no número de casos] é reflexo de um erro nosso, por causa da falta de informação sobre a vacinação. Atualmente sei que existem muito mais problemas em não vacinar do que em vacinar." E15

"Nós sabemos que é importante vacinar, não quero que minha filha pegue essas doenças, ela estando imunizada é melhor. Se imunizado já pode contrair, imagina sem." E4

"Eu não quero que meu filho pegue uma doença que já foi erradicado, eu não quero que ele passe por um adoecimento evitável. Não existe algo que não me leve a vacinar ele, nem essa questão da dor na aplicação, por que ela 'passa' logo." E14

"Eu vacino meu filho justamente prevenir o pior [óbito], prevenir as doenças e contribuir para a erradicação delas na sociedade." E12

A vacinação consolidou-se no Brasil, por meio do Programa Nacional de Imunização (PNI), o qual oferta mais de 15 imunógenos, e está cada vez mais complexo, seja pelo número de imunobiológicos ofertados como pelos esquemas vacinais. Desde a década de 90 a população possuía boa adesão a vacinação, com coberturas vacinais infantis no país acima de $95 \%$, a imunização das crianças tornou-se cultural, e visto como uma forma de cuidado e proteção parental (Sato, 2018), como foi identificado nesse estudo. Contudo tal taxa está em declínio desde 2016.

As mães desse estudo declaram terem possuído dúvidas em relação a imunização, mas que a informação foi o fator que as fez decidir sobre a adesão vacinal. A insegurança dos pais em vacinar está relacionado a diversos fatores, especialmente aos eventos adversos, e fomentados por movimentos antivacinação, os quais disseminam informações errôneas, associando as vacinas, especialmente a tríplice viral e a vacina conta o vírus papiloma humano ao surgimento de doenças, como o autismo e paralisia temporária, respectivamente (Armada, et al. 2020). Tal movimento desconsidera o rigor científico que permeia o desenvolvimento das vacinas (Sato, 2018; Mendes, et al. 2020).

Dessa forma, a informação é a principal forma dos profissionais de saúde conscientizarem a população da segurança das vacinas, bem como sua importância para a saúde individual e coletiva (Rodrigues, et al. 2020). A temática deve fazer parte as orientações frequentes nos serviços de saúde, para todos os indivíduos, e intensificado com gestantes e seus familiares, fomentando o compartilhamento de medos, dúvidas e anseios, de modo que empodere as pessoas para fazerem as escolhas mais seguras no cuidado ao seu filho e no autocuidado (Santos, et al. 2011; Nascimento, Cavalcanti \& Silva, 2020).

Considerando o contexto atual, as mães foram questionadas sobre malefícios da vacina, e as mesmas destacam que os benefícios os superam, mas citam que podem ocorrer efeitos adversos, além de dor por ser um procedimento invasivo, conforme falas a seguir:

“[...] Só que judia bastante deles, mas não tenho o que falar sobre malefícios.” E10 
“[...] Não penso em nada negativo, nós ficamos com dó da dor, mas tem que vacinar pra prevenir mais dor. Mas eu nem gosto de entrar pra ver, tenho dó.” E18

“[...] Não vejo fator negativo em vacinar, eu vejo em não vacinar.” E15

O medo de possíveis efeitos adversos gerados pela vacinação ainda são motivos de dúvidas sobre a seguridade da vacina, somado com informações equivocadas e o levantamento de hipótese sobre a real necessidade da imunização; o que pode gerar atraso ou recusa da vacinação. Com isso, esse fenômeno, o qual foi denominado pela Organização Mundial da Saúde (OMS) como "hesitação vacinal” tem caráter complexo; e necessita que os profissionais da saúde desenvolvam ações de comunicação para sanar as dúvidas e falta de confiança nas vacinas (Succi, 2018).

Estudos demonstram a atribuição de malefícios a vacina ao medo e insegurança dos pais em relação ao conhecimento e habilidade do profissional vacinador, a falta de conhecimento dos mesmos sobre as doenças preveníveis por cada vacina, a dificuldade de tempo e horário de funcionamento dos serviços, a falta do imunobiológico na UBS, e ainda, como citado pelas participantes desse estudo o receio de eventos adversos e o sofrimento da criança durante a administração da vacina (Buges, Pereira \& Almeida, 2020).

Dessa forma, os profissionais de saúde devem conhecer as principais dúvidas dos pais e estarem atualizados em relação ao tema, ofertando orientações frequentes e de qualidade para pais e usuários da unidade de saúde. Tal tema, ainda deve ser abordado por todos os profissionais que atendem a família de modo que eles compreendam que os benefícios superam os riscos, e não apenas a equipe de enfermagem, a qual é usualmente atribuída pelas famílias como quem oferta as orientações, a fim de consonância na fala dos profissionais, gerando mais segurança a família (Buges, Pereira \& Almeida, 2020).

Ainda, uma das mães, inclusive relacionam como negativo falta da inserção de alguns imunobiológicos na rede pública, o que faz com que a mesma precise adquirir na rede particular. Ainda, relata que algumas vacinas da rede particular apresentar menos reações adversas do que as da rede pública, conforme fala abaixo:

"Eu acredito que a única coisa negativa é que muitas vacinas não têm na rede pública, que são vacinas importantes e que tem alto custo, tipo a meningite B, que temos que dar na rede privada. As reações, tem algumas vacinas que na rede privada nós sabemos que tem menos reações e que na rede pública não tem, então acredito que não a vacina em si, mas na falta de não ter alguns tipos de vacina na rede pública." E11

A primeira vacina aplicada no Brasil foi em 1804, contra varíola, e deste então, o calendário vacinal infantil no Brasil avançou significativamente, e atualmente inclui 18 vacinas, que protegem contra diversas doenças virais e bacterianas. A inserção das vacinas no calendário segue o perfil o epidemiológico vigente no país, e a avaliação do custo-benefício do imunobiológico, permitindo a erradicação de algumas doenças no país (Morais Júnior, et al., 2018).

A rede pública de saúde atende a maior parte da população de forma gratuita, ofertando imunizantes nas maternidades e nas unidades básicas de saúde, ainda realiza busca ativa dos pacientes com vacinas atrasadas. A rede privada de imunização oferta um número maior de vacinas, e algumas são compostas pro micro-organismos acelulares, as quais possuem menos efeitos colaterais. Independente da rede as vacinas possuem a mesma função, e as vacinas publicas garante a mesma imunidade a criança (Hobe, et al. 2020).

Considerando a importância na prevenção de doenças, as mães participantes do presente estudo relatam não atrasarem as vacinas de seus filhos, somente com justificativa médica, exemplificado a seguir:

"Todas as vacinas estão em dia. Só atrasei dias, mas sempre dou no mês certinho. Foi questão de não poder ir no dia. " E2 
"[...]O meu filho teve alergia alimentar múltipla, passou por uma fase difícil e na época de vacinar eu não vacinei porque os médicos alergista e gastroenterologista aí pediram para esperar, quando liberaram eu levei ele para tomar." E14

"Não, apenas uma vez em que a pediatra pediu para demorar mais um pouquinho, porque minha filha estava com febre, então ela pediu pra esperar passar a febre, que era decorrente de uma infecção de garganta, para depois tomar a vacina" E8

O monitoramento do cumprimento do calendário vacinal é atribuição dos responsáveis pela criança, entretanto no serviço público é acompanhada pelos profissionais da unidade de saúde. O cumprimento dos períodos preconizados para cada imunizante é essencial para que este desenvolva a imunidade de forma adequada, por isso os profissionais de saúde fazem busca ativa das crianças com atraso vacinal. Ainda, algumas vacinas têm período de administração bem definido, e se não for realizado no mesmo a criança não recebe o calendário correto, influenciando na imunidade das mesmas (Morais Júnior, et al. 2020; Hobe, et al. 2020).

Contudo, quando se refere às suas vacinas as mães, referem ter mais dificuldades, relatando esquecimentos nas datas de administrações e reforços, bem como acesso as vacinas, conforme recortes abaixo:

"Sim, já atrasei as minhas vacinas, porque aonde moramos sempre está em falta. Aqui tinha, então eu já tomei” E5

“Já atrasei as minhas vacinas por ter esquecido, por causa do trabalho é dificil vir na unidade de saúde." E10

“[...]Sim, já atrasei tanto que agora quando engravidei eu nem tinha a carteirinha de vacinação, atrasei por desleixo, não achar importância, achar que a doença não existia também, mas agora já recebi todas. "E15

“[...] já atrasei por falta de tempo, de ir na unidade para receber, mas já está em dia.” E18

As mulheres relatam atraso em suas cadernetas de vacinação, devido ao esquecimento, dificuldade de acesso a unidade devido a unidade de saúde funcionar apenas em horário comercial, ou por não possuir vacinas nos serviços. A rede pública oferta cinco vacinas para adultos e idoso, e a imunização dos adultos é essencial para criar a imunidade de rebanho, garantido proteção para os indivíduos que não podem ser vacinados ou que não estão incluídos no calendário vacinal. Ainda, as mães ofertam imunização passiva recebida para as crianças durante a amamentação, por isso é essencial que estejam com as vacinas atualizadas (Domingues, et al. 2020). Ainda, no puerpério a atenção da mulher é voltada para o recém-nascido, e com isso pode ocorrer um déficit no autocuidado, o que pode contribuir para o atraso no calendário vacinal das mulheres. Assim, é necessário que os profissionais de saúde estendam suas orientações para a vacinação dos pais também.

As participantes relatam nunca terem recebido orientações e informações em relação a não vacinação dos filhos por parte dos profissionais da saúde, mas já receberam por familiares e amigos, mas que não as seguiram por não concordarem.

"Sempre os profissionais recomendam vacinar as crianças." E2

“Nunca recebi orientação para não vacinar pelos médicos que acompanham meu filho [...]” E12

“[...] uma tia minha que é médica não concorda com a vacina da febre amarela, mas aí a gente deixa ela com a opinião dela. Eu administrei a vacina no meu filho." E12

"Profissional de saúde não, mas da família sim. Uma tia minha que é mais idosa, diz em relação a vacina da gripe, que não iria vacinar porque essa vacina estava sendo aplicada para matar as pessoas e não pra curar da gripe. Mas é coisa de mais idade. Ela fala que não é para eu vacinar meus filhos e nem para me vacinar porque a gente iria morrer por causa da vacina." E8 
A falta de conhecimento por parte dos pais sobre as questões de imunização, criou um terreno fértil para a propagação de notícias falsas e mitos sobre a vacinação, e estas são uma das principais responsáveis pela diminuição da cobertura vacinal. A erradicação de algumas doenças fez com que sua gravidade não fosse conhecida pela população, a qual não compreende a necessidade de sua prevenção. Ainda, notícias falsas colocara em discussão questões que não eram popularmente debatidos, especialmente sobre efeitos adversos e composição das vacinais. A falta de conhecimento científico sobre os verdadeiros e reais benefícios da vacinação por parte da população faz com que movimentos antivacina ganhem força e impactem desde 2016 na cobertura vacinal (Buges, Pereira \& Almeida, 2020; Domingues, et al. 2020).

Dessa forma, a comunicação entre família e profissionais de saúde emerge como principal aliada na educação da população, por meio da discussão e divulgação de informações de qualidade sobre os desafios e benefícios da vacinação, empoderando as pessoas em relação aos conhecimentos da saúde. Para isso, é essencial que o profissional esteja atualizado, tenha postura dialógica e construa vínculo com a família, assim, pode-se tornar os pais mais confiantes em relação às vacinas, auxiliando na diminuição da hesitação vacinal (Succi, 2018).

Nesse interim, as participantes foram questionadas acerca do "Movimento Antivacina", a maioria das entrevistadas relatam pouco ou nenhum contato com o mesmo, e que apenas tiveram uma aproximação por meio da internet e redes sociais.

"Não tenho conhecimento, mas sempre escuto as pessoas dizendo que não vacinam o filho ou que a vacina não protege." E8

"Já vi alguma coisa na internet [sobre o movimento antivacina], mas eu não acredito. Pra falar a verdade eu vi mais falando sobre esse movimento nos Estados Unidos da América do que aqui no Brasil. Mas fico com receio, ainda mais porque nós moramos em um país quente e tem mais proliferação de vírus" E7

"Eu li no facebook quando estava gestante, então entrei na página e vi que algumas grávidas que estavam falando sobre não vacinar, eu achei um absurdo, mas nem cheguei a comentar por não saber discutir sobre isso, mas elas falavam que não iam levar os filhos para vacinar porque dava reação, a vacina fazia mal, que continha um monte de coisa [na composição das vacinas], umas coisas bem absurdas.” E17

"Já, eu já vi texto deles [movimentos antivacinas] relacionado com autismo e a vacina, mas nunca fui atrás disso, acho ridiculo." E14

"Já pela internet, mas eu acho besteira. Acredito que temos que vacinar, não concordo com essas ideias. Na verdade, eu li superficialmente, mas percebi que tem muita gente que é contra, mas eu não li a fundo a respeito." E18

Os grupos resistentes a vacinação, é um fenômeno crescente e intensificado pela obrigatoriedade na vacinação, o mesmo já foi identificado no Reino Unido e nos Estados Unidos, tal movimento fez com que a indústria farmacêutica alterasse o processo de fabricação de vacinas. No Brasil, tem suas fortes ligações com a Revolta da Vacina, o qual ocorreu de forma impositiva e violenta, contudo, a gravidade da epidemia fez com que a população desejasse ser vacinada (Domingues, et al. 2020).

Esses grupos disseminam, especialmente nas redes sociais, informações inverídicas sobre as vacinas, associando inclusive ao autismo, relação que cientificamente não existe. A internet possibilitou a rápida e indiscriminada disseminação dessas informações, atingindo um público cada vez maior. Tal fato pode estar relacionado a diminuição do índice de cobertura vacinal, o mesmo também pode ter relação com a alteração, em 2010, no sistema de registro de dados de vacinação no país (Saraiva \& Faria, 2019; Domingues, et al. 2020). 
A respeito dos impactos da diminuição da cobertura vacinal, as mães deste estudo ressaltam que pode haver a eminência de seus filhos contraírem doenças infecto contagiosas devido a lacuna imunológica que seria suprida pela vacina.

"O mais provável é que a criança que não recebeu a vacina tenha mais facilidade de contrair doenças, porque não vai ter anticorpos. Assim, pode passar para as outras crianças." E13

"Pode ter uma epidemia se cada um não vacinar seu filho. Várias pessoas vão se contaminar e ficar doentes, e ainda proliferar a doença." E4

"Como eu falei no começo da entrevista, se eu não vacinar meu filho ele vai adoecer ou morrer de uma doença prevenível. Também pode passar para os coleguinhas dele, ou até mesmo se eles não vacinarem podem passar para o meu filho. E acontecer como tá acontecendo com o sarampo." E14

"Pode acontecer até a morte das crianças, como agora tiveram vários casos de sarampo, e essa doença pode causar a morte. Então pra mim a vacinação de todos é essencial." E9

A imunização é uma decisão individual, mas que gera um impacto social, contribuindo para a diminuição da imunidade de rebanho o que pode vir a gerar surtos de doenças infectocontagiosas e o retorno de doenças já erradicadas (Passos \& Moraes Filho, 2020). A vacinação dos menores é decidida pelos pais e ou responsáveis, contudo, devido ao direito à saúde e a tutela de indisponibilidade dos direitos das crianças e dos adolescentes os mesmos têm o dever de vaciná-las (Paes, 2018; Nascimento, Cavalcanti, Silva, 2020).

Os movimentos anti-vacinas, são antigos e mais fortalecidos nos países de alta renda, entretanto o seu impacto negativo é maior em países com renda média e baixa (Trindade Passos \& de Moraes Filho, 2020).

Assim, é necessário mobilização de profissionais de saúde e gestores para proteger e fortalecer o programa nacional de imunizações, por meio da comunicação, campanhas publicitárias e do vínculo da população com as ações de vacinação. Destacando que os riscos de imunizar são menores do que o impacto da não vacinação na saúde das pessoas e coletividade, com impacto direto no adoecimento e na mortalidade por doenças preveníveis (Aps, et al., 2018; Sato, 2018).

\section{Considerações Finais}

O estudo identificou que as mães são as principais responsáveis pela vacinação das crianças, e o principal fator para a adesão vacinal é a prevenção e proteção para algumas doenças transmissíveis, evitando o adoecimento das crianças por doenças infectocontagiosas, assim, as mães associação a vacinação ao cuidado parental. Dessa forma, só atrasaram as vacinas ou deixaram de vacinar as crianças por indicação médica.

As participantes relatam que os benefícios da imunização superam os malefícios, e estes se relacionam a possiblidade de efeitos adversos, e a dor durante o procedimento invasivo. Ainda, que as dúvidas que tiveram sobre a vacinação foram supridas pelos profissionais de saúde, deixando-as segura para vacinar seus filhos.

Destacam que já leram sobre grupos anti-vacinação nas redes sociais e que já receberam orientações de familiares e amigos para não vacinar, mas que não as seguiram saberem dos benefícios, e do impacto na transmissão de doenças devido a diminuição da cobertura vacinal.

Assim, a comunicação e o vínculo entre profissionais e população é essencial para a adesão vacinal, bem como a atualização constante dos profissionais de saúde acerca da temática, e a disseminação em massa de informações cientificas sobre as vacinas, tanto das crianças, como dos adultos e idosos, a fim de conscientizar e empoderar as pessoas para a 
vacinação. Como lacuna desse estudo, apresenta-se um grupo restrito populacional, necessitando de pesquisas comparando camadas sociais, localização geográfica e escolaridade.

\section{Referências}

Armada, H. C. D., da Silva, M. R. B., de Carvalho, S. S. D. S., da Cunha, A. L., de Souza, D. R. S., \& da Silva, R. B. (2020). Influência dos responsáveis de adolescentes no impacto à adesão da vacina HPV. Saúde Coletiva (Barueri), 10(52), 2222-2231.

Aps, L. R. M. M., Piantola, M. A. F., Pereira, S. A., Castro, J. T., S., Fernanda A. O., \& Ferreira, L. C. S. (2018). Eventos adversos de vacinas e as consequências da não vacinação: uma análise crítica. Revista de Saúde Pública. 52(40):1-13.

Bardin, L. (2011). Análise de conteúdo. Edições 70.

Buges, N. M., Pereira, L. F. S., \& Almeida, R. F. S. (2020). Fatores que interferem na adesão dos pais e/ou responsáveis no cumprimento do calendário básico de vacinação infantil. Revista Amazônia: Science \& Health. 8(3): 91-105.

Domingues, C. M. A. S., Maranhão, A. G. K., Teixeira, A. M., Fantinato, F. F., \& Domingues, R. A. (2020). 46 anos do Programa Nacional de Imunizações: uma história repleta de conquistas e desafios a serem superados. Cadernos de Saúde Pública, 36 (2): e00222919.

Horbe, B. P., Santini, T. P., Adames, N., Haeffner, L. S. B., Naujorks, A. A., \& Backes, D. S. (2020). Public imunization sistem versus private immunization sistem: comparisons and attribution of nursing. Research, Society and Development. 9(5), e169953355.

Martins, K. M., Santos, W. L., \& Álvares, A. C. M. (2019). A importância da Imunização: revisão integrativa. Revista de Iniciação Científica e Extensão. 2(2):96-101.

Morais Júnior, S. L. A., de Menis, É. A. D. L., dos Santos Passos, V. C., Neves, L. O., \& Quezadas, A. C. (2018). A evolução histórica do calendário vacinal brasileiro infantil. Revista Enfermagem Atual In Derme. 85(23):71-75.

Mendes, C., Clara, I., Oliveira, S., \& Gonçalves, R. P. (2020). Os motivos da hesitação dos pais em vacinar: revisão integrativa da literatura. VITTALLE Revista de Ciências da Saúde. 32(3): 233-246.

Nascimento, L. C., Cavalcanti, A. C., Silva, M. M. M. (2020). Atuação da enfermagem na compreensão da família acerca da importância da imunização infantil: Revisão integrativa. REBES - Revista Brasileira de Educação e Saúde. 10(3): 115-120.

Paes, N. S. C. E. (2018). A vacinação obrigatória de crianças e de adolescentes em face da autonomia dos pais no exercício do poder familiar. Meritum, Revista de Direito da Universidade FUMEC. 13(2): 375-393.

Passos, F. T., \& de Moraes Filho, I. M. (2020). Movimento antivacina: revisão narrativa da literatura sobre fatores de adesão e não adesão à vacinação. Revista JRG de Estudos Acadêmico. 3(6): 170-181.

Rodrigues, A. L., Barros, M. F., Meirelles, S. F. D. R., \& Mantovani, D. D. P. (2020). Cobertura vacinal do HPV: uma analise sobre fatores que implicam na baixa adesão à vacina. Revista Transformar, 14(1), 560-574.

Santos, L. B., Barreto, C. C. M., Silva, F. L. S., Silva, K. C. O. (2011). Percepção das mães quanto à importância da imunização infantil. Rev. Rene. 12(3): $621-626$.

Saraiva, L. J., \& Faria, J. F. (2019). A Ciência e a Mídia: A propagação de Fake News e sua relação com o movimento anti-vacina no Brasil. Intercom Sociedade Brasileira de Estudos Interdisciplinares da Comunicação. 42(01), 01-15.

Sato, A. P. S. (2018). Qual a importância da hesitação vacinal na queda das coberturas vacinais no Brasil? Revista de Saúde Pública. 52(96): 1-9.

Silva, B. S., Souza, K. C. D., Souza, R. G. D., Rodrigues, S. B., Oliveira, V. C. D., \& Guimarães, E. A. D. A. (2020). Condições de estrutura e processo na implantação do Sistema de Informação de Imunização do Brasil. Revista Brasileira de Enfermagem. 73(4): e20180939.

Succi, R. C. M. Recusa vacinal: que é preciso saber. (2018). Jornal de Pediatria. 94 (6): 574-581.

Trindade Passos, F., \& de Moraes Filho, I. M. (2020). Movimento Antivacina: Revisão Narrativa da Literatura sobre Fatores de Adesão e Não Adesão à Vacinação. Revista JRG de Estudos Acadêmicos, 3(6), 170-181.

Yuzawa, L. S., Ferreira, W. F. da S., \& Oliveira, E. M. O. (2019). Políticas públicas brasileira de imunização e educação permanente: um recorte temporal bioético. Id onLine Revista de Psicologia. 13 (45):95-110. 